\title{
EFFECT OF LENGTH ON COMPRESSive STRAin SOFTENING OF CONCRETE
}

\author{
By Daniel C. Jansen, ${ }^{1}$ Member, ASCE, and Surendra P. Shah, ${ }^{2}$ Member, ASCE
}

\begin{abstract}
Aвstract: The concept of localization during the postpeak of compressive strain softening is presented. To explore localization in compression, a feedback-control method using a linear combination of displacement and force that partially subtracts the elastic response of the specimen to give a stable feedback signal is used. Results are presented from two test series (45 and $90 \mathrm{MPa}$ ) that use this method to test cylinders with length-to-diameter ratios ranging from 2.0 to $5.5 \mathrm{It}$ is shown that compression failure is in fact a localized phenomenon. The compressive fracture energy is divided into energy dissipated in the prepeak and the postpeak portions of the stress-deformation response. It is found that the amount of energy required to propagate the compression failure during postpeak is independent of length for this range of specimens. The compressive fracture energies are compared for the normal and high-strength concretes.
\end{abstract}

\section{INTRODUCTION}

Design of reinforced concrete structures is based on the ultimate strength capacity, which uses a portion of the postpeak or strain-softening branch of concrete in uniaxial compression. Subsequently, to calculate the ultimate structural capacity and to understand structural size and geometrical effects on ultimate strength, the usable portion of the postpeak behavior of concrete must be well characterized and taken into consideration. Improperly characterizing the postpeak behavior of concrete can lead to poor prediction of the ductility and ultimate axial deformation of columns and the rotational capacity, balanced steel ratio, and ultimate moment capacity of beams.

Strain softening of concrete occurs when microcracks, which begin forming during the prepeak portion of the stressstrain curve, coalesce to form a zone of damage, weakening the concrete so its load-carrying capacity is diminished. Additional deformation of the zone of damage weakens it further, and continued softening occurs. When specimens are short, damage appears to engulf the entire specimen. Due to the homogeneous appearance of the cracking of small tested specimens, it has generally been assumed that the compressive stress-strain curve is a uniform material property, hence a single stress-strain curve is typically used for a given compressive strength of concrete. Tensile load-deformation behavior of concrete has long been considered to be subject to localization effects; this was due in part to the fact that the load-deformation behavior of the crack could easily be distinguished from that of the undamaged bulk of the concrete. Hudson et al. (1972) discussed the possibility that a localized failure zone could be the cause of snapback observed with some rock specimens in compression. Over the last decade, compressive postpeak behavior has also been examined as a localized phenomenon using several different models. Because there is localization, the postpeak portion of the stress-strain curve is not only a material property but is dependent on specimen or measuring length. The postpeak response becomes steeper with increasing length (Choi et al., 1996; Hillerborg 1989; Rokugo and Koyanagi 1992; van Mier 1984; and Vonk 1992). In the zone where damage is occurring, dis-

\footnotetext{
'Asst. Prof., Dept. of Civ. and Envir. Engrg., Tufts Univ., Medford, MA 02155.

${ }^{2}$ Dir., Ctr. for Advanced Cement Based Mat., Northwestern Univ., Evanston, $\mathbf{L}$.
}

placement must continue to take place to soften or decrease the load-carrying capacity. Outside the zone where the localization is taking place during strain softening, the concrete expands axially as the stress is decreased or unloading occurs. Specimen geometry and boundary conditions will also affect the strain-softening behavior because they affect the size and shape of the failure zone relative to the overall specimen; investigating these influences is beyond the scope of the experimental work presented here.

This paper describes localization of compressive failure of concrete. A method for modeling the failure is presented. A test method that uses the characteristics of localization to control tests in compression that experience snapback is described. The results and modeling from an experimental program on normal and high-strength concrete are presented. The compressive fracture energy is calculated, and the results from the normal and high-strength concretes are compared.

\section{BEHAVIOR IN COMPRESSION}

It is useful to examine the modeling of tension localization of concrete to compare with localization in compression. Adapting a description of localization in tension from Elices and Planas (1989), a plausible description of the failure zone is described in Fig. 1, where the damaged zone has a nonuniform distribution as in Fig. 1(a). This damage zone grows in length, and the density increases during the postpeak portion of the test. Description of the cracking during postpeak has previously been characterized (Kotsovos 1983; Shah and Sankar 1987; Torrenti et al. 1993; van Mier 1984; and Vonk 1992). Due to the difficulty in modeling distributed damage, particularly when the zone length increases, it is easier to model the damage as a band, as shown in Fig. 1(b). Using the band model, two distinct areas of the concrete can be described, as shown in Fig. 2. In compression, localization initiates at the peak stress (Torrenti et al. 1993) or just prior to the peak stress (Shah and Sankar 1987). In either case, the shape of the stressstrain curve up to the peak can be considered approximately the same in both the bulk concrete and the eventual failure zone. During postpeak, the bulk concrete unloads, as shown in Fig. 2(a). The area described by this loading path is the prepeak energy per unit specimen volume, which is the dissipated energy due to microcracking during the procedure of loading up to peak. The same amount of energy per unit volume is dissipated up to the peak in the failure zone. During postpeak, however, additional energy is dissipated in the fracture zone, as shown in Fig. 2(b).

In Fig. 2, $L_{T}$ is defined as the total length of the specimen, and $L_{z}$ is the length of the failure zone. If the average strain within failure zone $\varepsilon_{z}$ is defined as the total displacement within the failure zone divided by the length of failure zone 


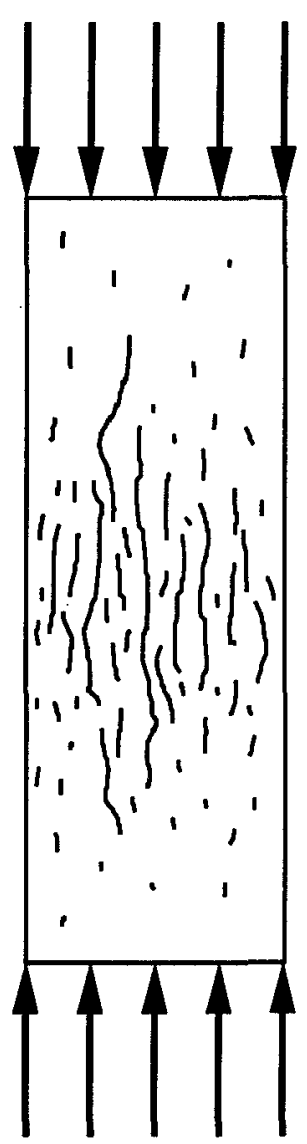

a)

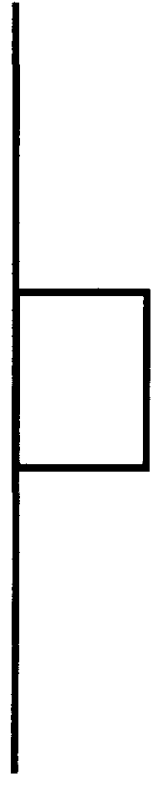

b)

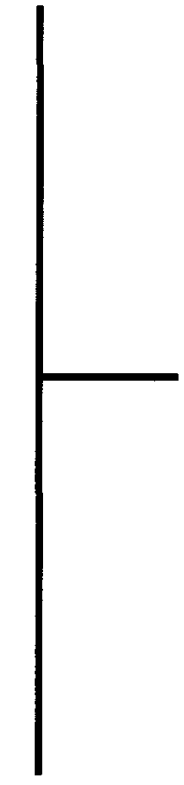

FIG. 1. Damage Distribution in Localization Compression Models: (a) Distributed Damage; (b) Band-Damage Distrlbutlon; (c) Line-Damage Distribution

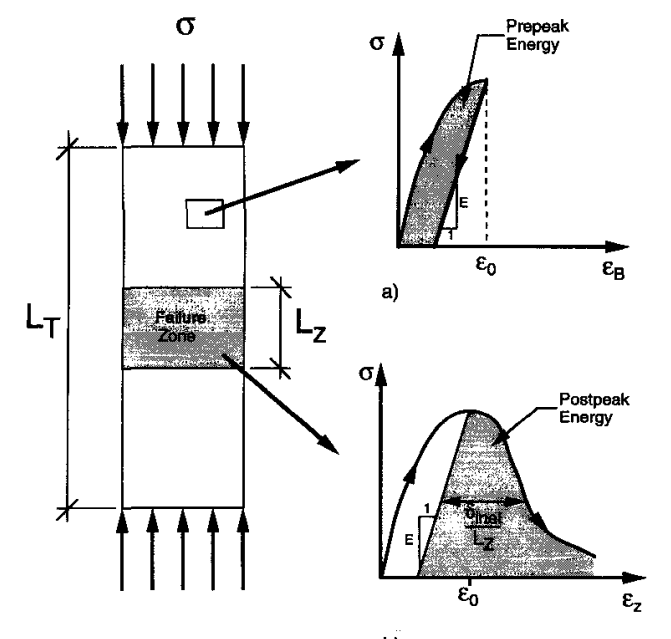

b)

FIG. 2. Band Model for Localization Behavior in Compression: (a) Bulk Concrete Behavior, Length $=L_{T}-L_{z ;}$ (b) Failure Zone Behavior, Length $=L_{z}$

$L_{z}$, then $\varepsilon_{z}$ can be thought of as being composed of two components: one similar in response to the bulk concrete, $\varepsilon_{B}$, and the additional inelastic strain occurring in the localized zone. If it is assumed that the inelastic displacement of the localized zone $\left(\delta_{\text {inel }}\right)$ is independent of the length of the localized zone described by the linear damage model in Fig. 1(c), then one can write

$$
\varepsilon_{z}=\varepsilon_{B}+\left(\delta_{\text {inee }} / L_{z}\right)
$$

This breakdown of the strains is a safe assumption as long as the failure zone is shorter than the specimen length (Bazant 1989).

\section{EXPERIMENTAL DETAILS}

\section{Mix Designs}

Two different strengths of concrete were cast for this investigation, nominally 45 and $90 \mathrm{MPa}$. Graded $9 \mathrm{~mm}$ river pea gravel was used in both batches for the coarse aggregate. Graded \#2 sand was used in both batches as the fine aggregates. Both the gravel and the sand were oven dried prior to mixing and have effective absorptions of 1.3 and $2.3 \%$, respectively. ASTM Type I ordinary portland cement was used for both batches of concrete. For the $90 \mathrm{MPa}$ concrete, $12.5 \%$ of the cementitious material was silica fume. The silica fume was used in a slurry form with $50 \%$ water. A high-range waterreducing admixture conforming to ASTM C-494 as a Type F admixture was added to the $90 \mathrm{MPa}$ batch in order to obtain a workable mix. Table 1 lists the mix proportions for the two concretes. Note that the amount of water shown includes the water absorbed by the aggregates and the water contained in the silica fume slurry and superplasticizer. The water to cementitious ratios were 0.44 and 0.27 for the normal and highstrength concretes, respectively.

\section{Casting, Curing, and Specimen Preparation Procedures}

The concrete was mixed in a $0.15 \mathrm{~m}^{3}$ drum-type mixer. Two $102 \times 203 \mathrm{~mm}$ specimens (designated $2.0 \mathrm{C}$ and $2.0 \mathrm{D}$ ) were cast in disposable plastic cylinders as reference cylinders. Nine specimens were cast in schedule 40 polyvinyl chloride (PVC) tubing with nominal inner diameters of $102 \mathrm{~mm}$ : three were $500 \mathrm{~mm}$ and six were $600 \mathrm{~mm}$ in length. The concrete was cast vertically in $100 \mathrm{~mm}$ lifts and consolidated on a vibrating table after placement of each lift.

Two days after casting, the specimens were demolded by cutting the PVC tubes with a table saw and then placed into a $100 \%$ humidity and $20^{\circ} \mathrm{C}$ chamber. The concrete was cured for the next 12 days ( 2 weeks) and 40 days (6 weeks) for the normal and high-strength batches before being placed in a $50 \%$ humidity and $20^{\circ} \mathrm{C}$ chamber. The specimens were tested at 28 \pm 1 and $56 \pm 1$ days after casting for the normal and highstrength concretes, respectively.

The specimens were cut to their proper lengths following Table 2: a total of 13 specimens were cut from the nine cylinders. Two specimens for each of the height-to-diameter ratios (H:D) of 2.0, 2.5, 3.0, 3.5, 4.5, and 5.5 plus one of $\mathrm{H}: \mathrm{D}$ of 4.0 were cut for each batch of concrete. In an attempt to remove casting end effects, $10 \mathrm{~mm}$ were cut from the bottom of each original cylinder; then either one or two specimens were cut from the bottom, typically leaving the top 50 to 100 $\mathrm{mm}$ of the original cylinder for disposal. The relevance of the casting location becomes apparent when interpreting the results. Table 2 notes whether the specimen was cut from the top or bottom of the original cylinder; if no designation is

TABLE 1. MIX Proportions

\begin{tabular}{|c|c|c|}
\hline $\begin{array}{c}\text { Material } \\
\text { (1) }\end{array}$ & $\begin{array}{c}\text { Normal } \\
\text { strength } \\
(45 \mathrm{MPa}) \\
(2)\end{array}$ & $\begin{array}{c}\text { High } \\
\text { strength } \\
(90 \mathrm{MPa}) \\
(3) \\
\end{array}$ \\
\hline $\begin{array}{l}\text { Cement }\left(\mathrm{kg} / \mathrm{m}^{3}\right) \\
\text { Silica fume }\left(\mathrm{kg} / \mathrm{m}^{3}\right) \\
\text { Water }\left(\mathrm{kg} / \mathrm{m}^{3}\right) \\
9 \mathrm{~mm} \text { pea gravel }\left(\mathrm{kg} / \mathrm{m}^{3}\right) \\
\text { Graded \#2 sand }\left(\mathrm{kg} / \mathrm{m}^{3}\right) \\
\text { Superplasticizer }\left(1 / \mathrm{m}^{3}\right)\end{array}$ & $\begin{array}{r}381 \\
0 \\
199 \\
994 \\
806 \\
0\end{array}$ & $\begin{array}{r}479 \\
61 \\
173 \\
973 \\
758 \\
7\end{array}$ \\
\hline
\end{tabular}


TABLE 2. Specimen Cutting Schedule, Dimensions, and Densities

\begin{tabular}{|c|c|c|c|c|c|c|c|c|}
\hline \multirow[b]{2}{*}{$\begin{array}{c}\text { Specimen } \\
\text { designation } \\
\text { (1) }\end{array}$} & \multicolumn{2}{|c|}{ Cutting Schedule } & \multicolumn{3}{|c|}{$\begin{array}{c}\text { Normal Strength } \\
(45 \mathrm{MPa})\end{array}$} & \multicolumn{3}{|c|}{$\begin{array}{l}\text { High Strength } \\
(90 \mathrm{MPa})\end{array}$} \\
\hline & $\begin{array}{c}\text { Uncut cylinder } \\
\text { length (mm) } \\
\text { (2) }\end{array}$ & $\begin{array}{c}\text { Top or bottom } \\
\text { cut } \\
\text { (3) }\end{array}$ & $\begin{array}{c}\text { Average } \\
\text { diameter } \\
(\mathrm{mm}) \\
(4)\end{array}$ & $\begin{array}{c}\text { Length } \\
\text { with caps } \\
(\mathrm{mm}) \\
(5)\end{array}$ & $\begin{array}{c}\text { Density } \\
\left(\mathrm{kg} / \mathrm{m}^{3}\right) \\
(6)\end{array}$ & $\begin{array}{c}\text { Average } \\
\text { diameter } \\
(\mathrm{mm}) \\
(7) \\
\end{array}$ & $\begin{array}{l}\text { Length } \\
\text { with caps } \\
(\mathrm{mm}) \\
(8)\end{array}$ & $\begin{array}{c}\text { Density } \\
\left(\mathrm{kg} / \mathrm{m}^{3}\right) \\
(9)\end{array}$ \\
\hline $\begin{array}{l}2.0 \mathrm{~A} \\
2.0 \mathrm{~B} \\
2.0 \mathrm{C} \\
2.0 \mathrm{D} \\
2.5 \mathrm{~A} \\
2.5 \mathrm{~B} \\
3.0 \mathrm{~A} \\
3.0 \mathrm{~B} \\
3.5 \mathrm{~A} \\
3.5 \mathrm{~B} \\
4.0 \mathrm{~B} \\
4.5 \mathrm{~A} \\
4.5 \mathrm{~B} \\
5.5 \mathrm{~A} \\
5.5 \mathrm{~B}\end{array}$ & $\begin{array}{l}600 \\
600 \\
203 \\
203 \\
600 \\
600 \\
600 \\
600 \\
600 \\
600 \\
500 \\
500 \\
500 \\
600 \\
600\end{array}$ & $\begin{array}{l}\text { Top } \\
\text { Bottom } \\
\text { Whole } \\
\text { Whole } \\
\text { Top } \\
\text { Bottom } \\
\text { Bottom } \\
\text { Top } \\
\text { Bottom } \\
\text { Top } \\
\text { Whole } \\
\text { Whole } \\
\text { Whole } \\
\text { Whole } \\
\text { Whole }\end{array}$ & $\begin{array}{l}101.1 \\
100.9 \\
101.3 \\
101.4 \\
101.2 \\
100.8 \\
101.0 \\
101.0 \\
101.0 \\
101.0 \\
101.0 \\
100.9 \\
101.1 \\
101.0 \\
101.0 \\
101.0^{n}\end{array}$ & $\begin{array}{l}208.7 \\
207.2 \\
208.6 \\
208.8 \\
260.9 \\
259.3 \\
312.3 \\
313.0 \\
357.1 \\
362.7 \\
416 \\
465 \\
466 \\
565 \\
566\end{array}$ & $\begin{array}{c}2,368 \\
2,400 \\
2,386 \\
2,371 \\
2,363 \\
2,402 \\
2,378 \\
2,374 \\
2,379 \\
2,379 \\
2,382 \\
2,389 \\
2,376 \\
2,374 \\
2,380^{a}\end{array}$ & $\begin{array}{l}101.4 \\
101.1 \\
101.3 \\
101.3 \\
101.1 \\
101.0 \\
101.0 \\
101.2 \\
101.1 \\
101.0 \\
101.1 \\
101.3 \\
101.1 \\
101.1 \\
101.2 \\
101.2^{\mathrm{a}}\end{array}$ & $\begin{array}{l}210.4 \\
208.5 \\
211.1 \\
209.7 \\
260.7 \\
260.2 \\
310.4 \\
311.5 \\
361.4 \\
362.7 \\
416 \\
464 \\
464 \\
566 \\
564\end{array}$ & $\begin{array}{l}2,451 \\
2,467 \\
2,463 \\
2,440 \\
2,451 \\
2,466 \\
2,471 \\
2,450 \\
2,464 \\
2,463 \\
2,439 \\
2,448 \\
2,456 \\
2,464 \\
2,458 \\
2,457^{\natural}\end{array}$ \\
\hline
\end{tabular}

Average.

given, then it is the only specimen cut from the given cylinder. Both ends of the specimens were capped with a high-strength sulfur mortar capping compound three days prior to testing. The cap thicknesses averaged $2-4 \mathrm{~mm}$ each. The lengths, averages of two diameters, and weights were measured and are shown in Table 2 . The averaged diameters are used to calculate the cross-sectional area and later for the stresses. The lengths are needed for determining the measurement gauge lengths.

\section{Feedback-Control Test Method}

Due to the length of the specimens and the brittleness of high-strength concrete, snapback occurs in some of the forcedisplacement curves; subsequently, a control method that could provide stable control during the postpeak portion of the test was needed. Normally, circumferential control (Hudson et al. 1972; Jansen et al. 1995; and Shah et al. 1981) would be used; however, with the longer specimens the zone of failure does not always occur at the middle of the specimen. In this case, the circumferential transducer being used as the feedback control would not provide stable control of the test. An alternative method of feedback control that is a linear combination of force and displacement was originally presented by Okubo and Nishimatsu (1985) and later used and discussed by others (de Larrard and Malier 1992; Jansen and Shah 1993; Jansen and Shah 1994; Okubo et al. 1990; and Rokugo et al. 1986). The method of partial elastic subtraction measures the total specimen deformation and subtracts part of the elastic deformation, leaving inelastic deformation as a stable feedback signal (FS). FS can be calculated as

$$
\text { Feedback }=\mathrm{FS}=\delta_{T}-\alpha\left(F / K_{0}\right)
$$

where $\delta_{T}=$ total axial specimen displacement; $F=$ measured force on the specimen; $K_{0}=$ the specimen stiffness; and $\alpha=$ coefficient that must be a positive value less than 1 . This linear combination of force and displacement was digitally created by the test-machine controller. If $\alpha=1.0$ was used, this would be the same as using $\varepsilon_{\text {inel }}$ described earlier as FS during postpeak.

Fig. 3 shows the combining of deformation and force where severe snapback occurred to give a monotonic FS. In this experiment, the concrete specimen was nominally $102 \mathrm{~mm}$ in diameter and $560 \mathrm{~mm}$ in length and had a compressive strength of about $90 \mathrm{MPa}$. To understand this combination, one can think of subtracting a value proportional to the change in force from the displacement during prepeak loading and then adding it back as the force decreases along the descending branch, or alternatively removing a portion $(\alpha)$ of the elastic response of the specimen to obtain the stable inelastic response. Another viewpoint is shown in Fig. 4. When $\alpha=0.0$, the feedback axis is horizontal $(\Theta=0)$, which corresponds to axial deformation control. When $\alpha=1.0$, the feedback axis has rotated until it is perpendicular to the elastic stiffness $K_{0}$. The axial deformation rate can be obtained by differentiating (2) with respect to time and rearranging to obtain

$$
\frac{d \delta_{T}}{d t}=\frac{d(\mathrm{FS})}{d t}+\frac{\alpha}{K_{0}} \frac{d F}{d t}
$$

The axial strain rate at which tests are run can be defined as the axial strain rate at the peak force when $d F / d t=0$. At the peak force, the axial deformation rate is determined as $d \delta_{T} l d t$ $=d(\mathrm{FS}) / d t$.

The requirement for obtaining a stable signal is rotation of the feedback axis in Fig. 4 so the failure envelope describes an always increasing signal with respect to the feedback axis. Also, the rotation cannot be so large that FS is produced, which decreases during the loading (prepeak) portion of the test. This second requirement also ensures that unloading of the specimen will not occur; if the specimen is unloaded at any time during the test, then a decreasing signal must be produced. The rotation of the axis must be such that

$$
K_{0} \leq \frac{1}{\alpha} K_{0} \leq K_{d}
$$

where $K_{d}=$ minimum tangent to the descending branch of the curve. It should be noted if $\alpha$ were equal to 1 , then FS would be obtained, which would not change at the point when the tangent stiffness was $K_{0}$, which is an unstable signal. Fig. 5 shows the actual plots of the stress-feedback and stress-displacement curves together for the same specimen shown in Fig. 3. Note the stress-feedback curve is always increasing along the $x$-axis, whereas the stress-displacement curve decreases with respect to the $x$-axis during postpeak.

This FS is very sensitive to small changes in force or deformation, and the closer $\alpha$ is to 1 , the more sensitive it becomes. A result of the sensitivity, simultaneous up and down cycling of the force and displacement is visible in Fig. 5. Es- 

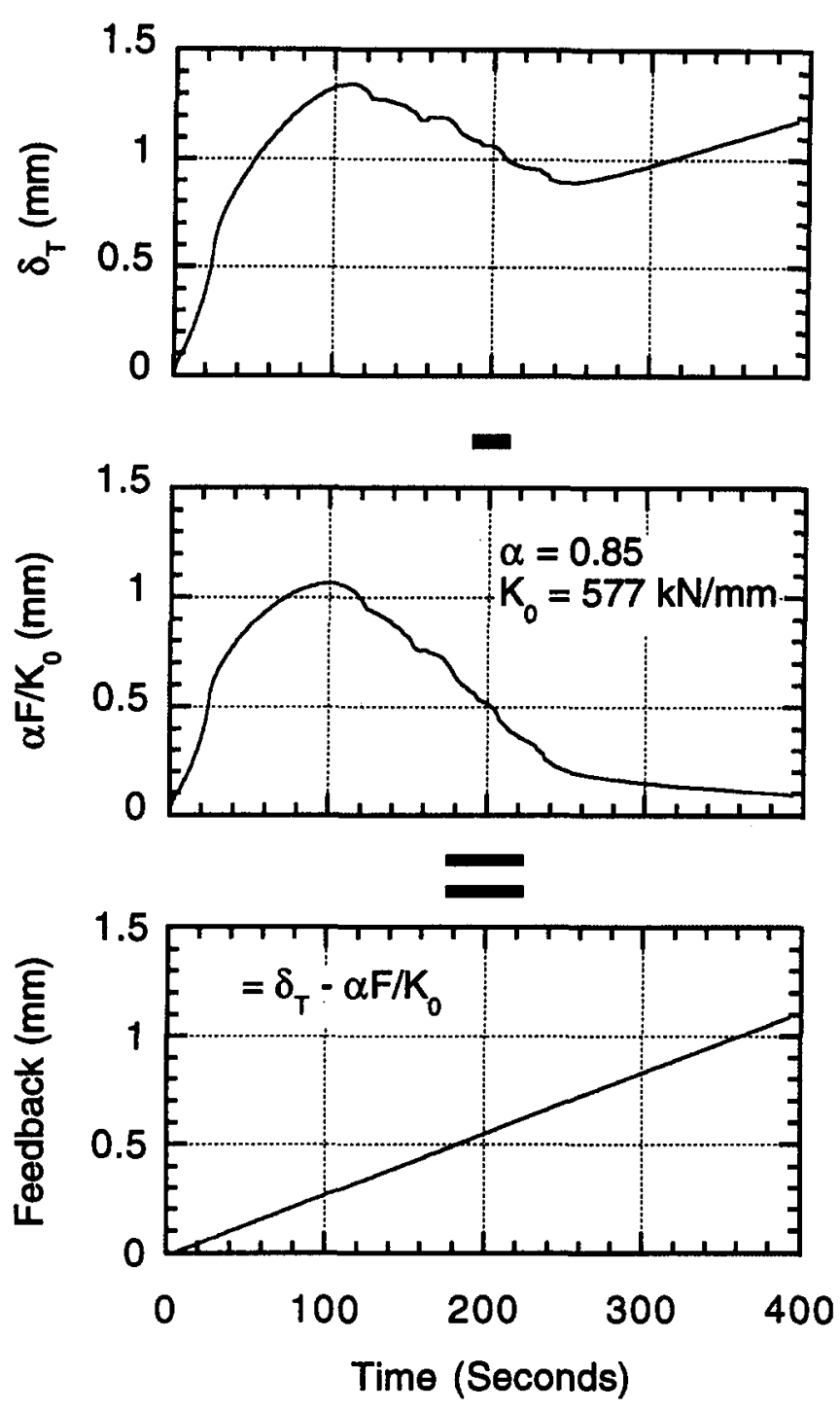

FIG. 3. Composition and Combination of Feedback Signal (Envelope of Measured Data)

sentially, the force and displacement can decrease together and hardly change FS. This is because the slope of the unloading of the stress-displacement curve is nearly perpendicular to the FS axis. If the FS curve of Fig. 5 is examined closely, the cycling is near vertical, which means FS hardly changes as the cycling occurs. If $\alpha$ were equal to 1 , then the load could be completely removed along with the displacement along the elastic curve (slope $=K_{0}$ ) without changing FS. Jansen and Shah (1993) further describe this sensitivity. The appropriate $\alpha$ must be selected for each individual test machine and loading configuration; however, $\alpha=0.85$ seems to be a good general number for concrete in compression. The stress-strain curve is obtained by taking the envelope of this cycling curve. For the rest of this paper, when curves are presented, it should be understood that they are the envelopes prescribed by this cycling.

\section{Experimental Setup}

An MTS servohydraulic closed-loop test machine with a 4.4 MN capacity was used for all tests. The frame of the machine has a designed stiffness of about $13 \mathrm{MN} / \mathrm{mm}$; however, with the spherically seated top platen, actuator, spacers, and fixed bottom platen, the stiffness has been measured as low as 2.5 $\mathrm{MN} / \mathrm{mm}$. A personal computer controls the test machine as

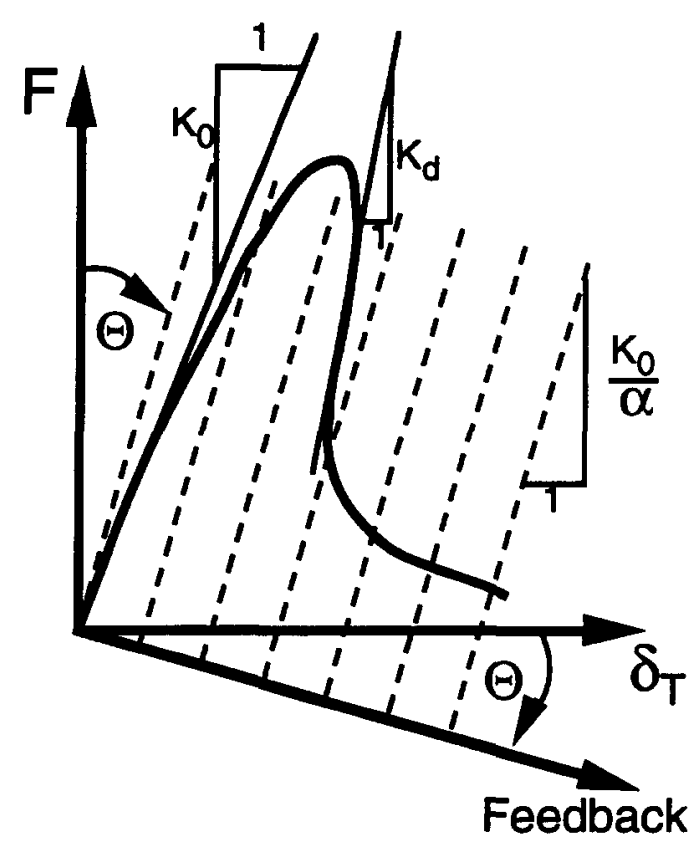

FiG. 4. Axls Rotation for Feedback SIgnal

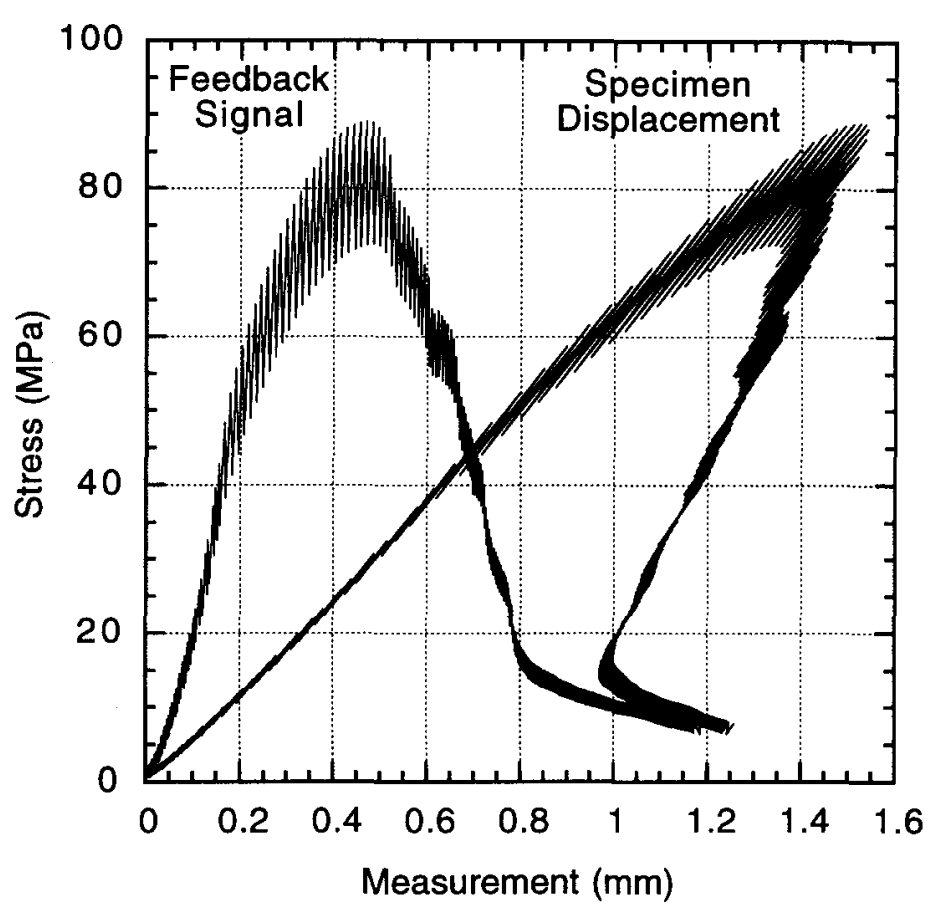

FIG. 5. Comparison of Feedback and Displacement Signals

well as performs the function of data acquisition. The spherically seated platen has a mechanism that allowed it to be locked after an initial load had been applied to provide proper seating of the specimen and prevent rotation of the platen during the test.

Four linear variable differential transformers (LVDTs), each with a range of $\pm 2.5 \mathrm{~mm}$, and one strain compressometer were used to measure displacements and strains, as can be seen in the photograph in Figs. 6(a) and (b). Two LVDTs attached diametrically opposed to the faces of the platens measured the platen-to-platen displacement. The average of the platen-toplaten displacements is called $\delta_{p}$ and was used as the displacement measurement in the calculation of FS. The other two LVDTs were attached diametrically opposed on a rigid frame, which was fixed to the specimen surface $12.5 \mathrm{~mm}$ from the bottom of the specimen. A second rigid frame was attached to 
(a)

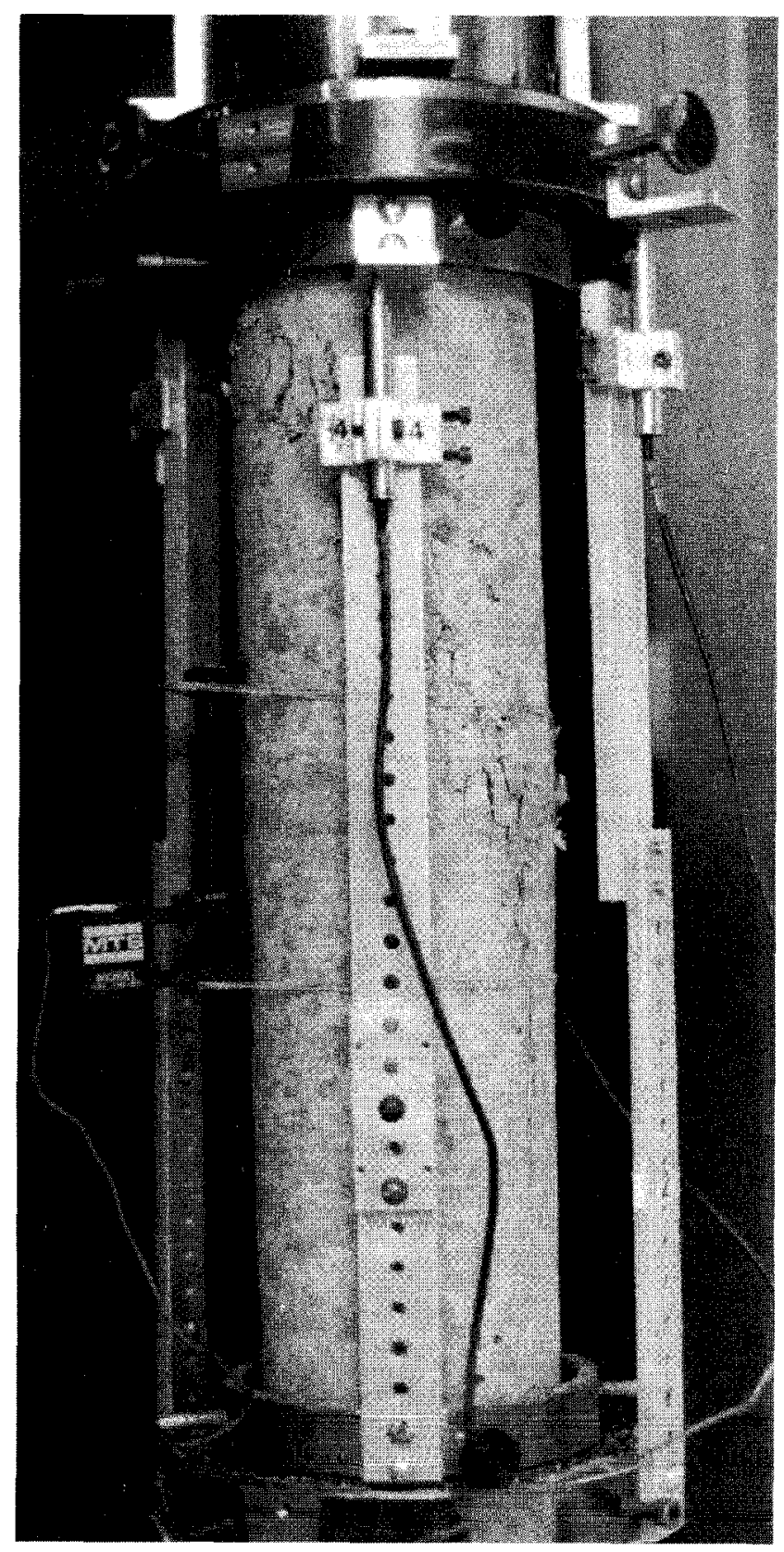

(b)

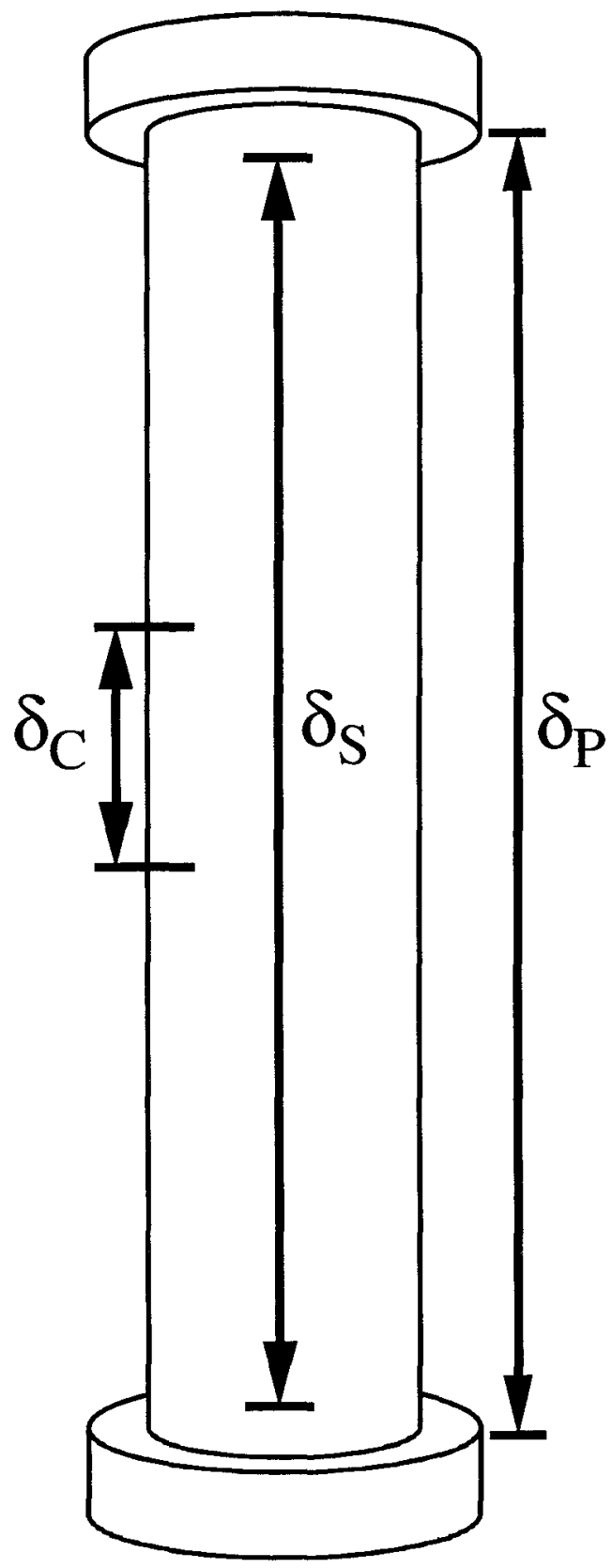

FIG. 6. Specimen Setup during Testing: (a) Photograph; (b) Drawing

the specimen $12.5 \mathrm{~mm}$ from the top of the specimen and provided a reaction for these two LVDTs. The average of the displacements measured by these surface-mounted LVDTs is called $\delta_{s}$. The surface-mounted LVDTs were necessary so the displacements due to the softer capping compounds relative to the concrete and displacements at the interfaces between the specimen and platen would not be measured (Jansen et al. 1995). The compressometer used during the tests had a gauge length of $102 \mathrm{~mm}$ and consistently gave erratic responses during postpeak due to cracking and spalling under the attachment points of the transducer, similar to the findings of others (Choi et al., 1996; Glavind and Stang 1991; Jansen et al. 1995; and Kotsovos 1983). The strain measured by the compressometer is designated $\varepsilon_{c}$. The surface-mounted LVDTs did not normally experience this problem since the ends of the specimens were not lubricated and the confining stresses from the platens prevented significant cracking and spalling from occurring near the ends of the specimen.

\section{Experimental Procedure}

Each specimen was loaded three times to approximately $45 \%$ of the peak load. The maximum tangential stiffness, $K_{0 p}$, was computed from the upward leg of the third loading cycle measured between the force and $\delta_{p}$. The three cycles up to $45 \%$ of the peak stress also served the function to allow the gauges and specimen to seat and remove the hysteretic mechanical displacements from the system. Upon reaching the peak load on the third cycle, the load was held and the spherically seated platen was locked to prevent rotation. The load was then reduced to less than $4 \mathrm{kN}$.

The constants $K_{0 p}$ and $\alpha=0.85$ were put into (3), and $\delta_{p}$ and $F$ were continuously monitored to produce FS. FS was increased linearly with time at a rate that gave an equivalent axial strain rate of $5 \mu \varepsilon / \mathrm{s}$ at the peak stress.

The data was acquired by the computer controlling the test in two manners simultaneously; data points were taken at a 
TABLE 3. Stresses and Strains at Peak

\begin{tabular}{|c|c|c|c|c|c|c|c|c|}
\hline \multirow[b]{2}{*}{$\begin{array}{l}\text { Specimen } \\
\text { designation } \\
\text { (1) }\end{array}$} & \multicolumn{4}{|c|}{ Normal Strength (45 MPa) } & \multicolumn{4}{|c|}{ High Strength (90 MPa) } \\
\hline & $\begin{array}{c}\sigma_{0} \\
(\mathrm{MPa}) \\
(2) \\
\end{array}$ & $\begin{array}{c}\varepsilon_{\infty} \\
(m \mathrm{~mm} / \mathrm{m}) \\
(3)\end{array}$ & $\begin{array}{c}\varepsilon_{p 0} \\
(\mathrm{~mm} / \mathrm{m}) \\
(4)\end{array}$ & $\begin{array}{c}\varepsilon_{\infty} \\
(\mathrm{mm} / \mathrm{m}) \\
(5)\end{array}$ & $\begin{array}{c}\sigma_{0} \\
(\mathrm{MPa}) \\
(6)\end{array}$ & $\begin{array}{c}\varepsilon_{\infty} \\
(\mathrm{mm} / \mathrm{m}) \\
(7)\end{array}$ & $\begin{array}{c}\varepsilon_{p o} \\
(\mathrm{~mm} / \mathrm{m}) \\
(8)\end{array}$ & $\begin{array}{c}\varepsilon_{\infty} \\
(\mathrm{mm} / \mathrm{m}) \\
(9)\end{array}$ \\
\hline $\begin{array}{l}2.0 \mathrm{~A} \\
2.0 \mathrm{~B} \\
2.0 \mathrm{C} \\
2.0 \mathrm{D} \\
2.5 \mathrm{~A} \\
2.5 \mathrm{~B} \\
3.0 \mathrm{~A} \\
3.0 \mathrm{~B} \\
3.5 \mathrm{~A} \\
3.5 \mathrm{~B} \\
4.0 \mathrm{~A} \\
4.5 \mathrm{~A} \\
4.5 \mathrm{~B} \\
5.5 \mathrm{~A} \\
5.5 \mathrm{~B}\end{array}$ & $\begin{array}{l}42.8 \\
55.6 \\
49.0 \\
48.7 \\
44.1 \\
55.4 \\
50.1 \\
45.7 \\
51.4 \\
43.1 \\
46.8 \\
46.7 \\
47.7 \\
45.8 \\
45.4\end{array}$ & $\begin{array}{l}1.98 \\
2.20 \\
- \\
2.05 \\
2.27 \\
2.10 \\
2.01 \\
2.09 \\
1.85 \\
1.87 \\
1.91 \\
2.00 \\
1.85 \\
1.84\end{array}$ & $\begin{array}{l}2.16 \\
2.48 \\
- \\
2.21 \\
2.47 \\
2.26 \\
2.17 \\
2.23 \\
1.96 \\
1.99 \\
1.99 \\
2.09 \\
1.92 \\
1.90\end{array}$ & $\begin{array}{c}2.14 \\
2.43 \\
- \\
- \\
2.19 \\
2.35 \\
2.07 \\
2.30 \\
2.12 \\
2.21 \\
1.92 \\
1.84 \\
2.21 \\
1.96 \\
1.87\end{array}$ & $\begin{array}{l}90.9 \\
93.1 \\
86.3 \\
90.3 \\
88.5 \\
88.1 \\
93.2 \\
90.8 \\
90.1 \\
92.6 \\
88.2 \\
88.6 \\
91.0 \\
90.0 \\
90.1\end{array}$ & $\begin{array}{l}2.44 \\
2.44 \\
- \\
- \\
2.38 \\
2.32 \\
2.54 \\
2.51 \\
2.45 \\
2.56 \\
2.39 \\
2.40 \\
2.46 \\
2.44 \\
2.51\end{array}$ & $\begin{array}{l}2.86 \\
2.97 \\
- \\
2.74 \\
2.69 \\
2.84 \\
2.81 \\
2.68 \\
2.77 \\
2.59 \\
2.68 \\
2.66 \\
2.62 \\
2.63\end{array}$ & $\begin{array}{l}2.58 \\
2.51 \\
- \\
2.35 \\
2.54 \\
2.71 \\
2.75 \\
2.71 \\
2.62 \\
2.31 \\
2.31 \\
2.58 \\
2.43 \\
2.53\end{array}$ \\
\hline & $\begin{array}{c}47.9^{a} \\
3.9^{b}\end{array}$ & $\begin{array}{l}2.00^{a} \\
0.14^{b}\end{array}$ & $\begin{array}{l}2.14^{\mathrm{a}} \\
0.19^{\mathrm{b}}\end{array}$ & $\begin{array}{l}2.12^{\mathrm{a}} \\
0.19^{\mathrm{b}}\end{array}$ & $\begin{array}{c}90.1^{\mathrm{a}} \\
2.0^{\mathrm{b}}\end{array}$ & $\begin{array}{l}2.45^{\mathrm{n}} \\
0.07^{\mathrm{b}}\end{array}$ & $\begin{array}{l}2.73^{\mathrm{a}} \\
0.11^{\mathrm{b}}\end{array}$ & $\begin{array}{l}2.53^{\mathrm{a}} \\
0.15^{\mathrm{b}}\end{array}$ \\
\hline
\end{tabular}

"Average.

Standard deviation.

rate of $1 \mathrm{~Hz}$ and at each peak of the cycling caused by FS. By taking data points at the peaks of cycling, the envelope described by cycling can be defined. The data taken at a constant rate (time-based data) were important because cycling did not always occur over the entire test.

\section{EXPERIMENTAL RESULTS}

The average displacements for the two gauge lengths of LVDTs, $\delta_{p}$ and $\delta_{s}$, were divided by their individual gauge lengths (total specimen length and specimen length less 25 $\mathrm{mm}$, respectively) to produce average strains, designated as $\varepsilon_{p}$ and $\varepsilon_{s}$. Using these values plus the strain measured by the compressometer $\left(\varepsilon_{c}\right)$, the tangent moduli $\left(E_{s}, E_{p}\right.$, and $\left.E_{c}\right)$ were determined at $45 \%$ of the peak stress for all three measuring gauge lengths. The initial section of the curve to $45 \%$ of the peak stress was replaced by a straight line with the slope equal to the corresponding tangent stiffness.

\section{Stresses and Strains up to Peak}

Table 3 lists the peak stresses, $\sigma_{0}$, and the strains at peak stress for all specimens. A large variation in the peak stresses was found for the normal-strength concrete. The variation is less a function of specimen length as it is dependent on whether it was taken from the top or bottom of one of the cast cylinders, as described earlier. The normal-strength specimens cut from the top of the cast cylinders were considerably weaker than those cut from the bottom. Two possibilities could be responsible for this effect: bleeding could weaken the top section of the cylinders, or the bottom section could be compacted better due to the weight of the concrete above and greater compaction time. The high-strength specimens do not show this trend, which leads to the conclusion that highstrength concrete is less sensitive to compaction and bleeding. Kotsovos (1983) reported little to no effect on the compressive strength of concrete due to boundary conditions such as restraint from loading platens when the height-to-diameter ratios exceed 2.5 , which aids the conclusion that any perceivable trend in strengths as specimens get longer are only different due to statistical sampling.

The strains measured at peak stress by surface LVDTs, $\varepsilon_{s 0}$, seem to decrease with specimen length for normal-strength concrete; however, this decrease is not statistically significant and may be due only to scatter. On the other hand, this effect would provide evidence supporting the initiation of localization before peak. For the normal-strength concrete, when there is a significant difference between the $\varepsilon_{s 0}$ for a single specimen length, it corresponds to differences in peak stresses as mentioned previously. The platen-to-platen strain at ultimate $\varepsilon_{p 0}$ does decrease significantly with increasing specimen length. This trend is due to the decrease in the relative length of the specimen ends to the overall length of the specimen. The soft capping compound and interfaces between specimen and platens contribute additional displacement to the measurements taken by the platen-to-platen LVDTs. As the specimens become longer, these additional displacements have relatively smaller influence on the total strain. The compressometer strain measurements at peak $\varepsilon_{c o}$ have a greater standard deviation than the surface strains $\varepsilon_{s 0}$, as shown at the bottom of Table 3: \pm 0.19 versus \pm 0.14 and \pm 0.15 versus $\pm 0.07 \mathrm{~mm} /$ $\mathrm{m}$ for the normal and high-strength concretes, respectively. This difference is due mostly to there only being one compressometer, which would make it vulnerable to small eccentricities in loading.

Examining the tangent moduli, listed in Table 4, a considerable difference is found between the moduli measured by the three types of transducers. The moduli measured by the platen-to-platen LVDTs, $E_{p}$, have the lowest values that can be contributed to the softness of the capping compound and the interfaces between the specimen and platens. Confirming this conclusion is that $E_{p}$ increases as the length of the soft ends relative to the total length of the specimen decreases. A simple-series spring model [described in more detail in Jansen et al. (1995)] can be created to find the average modulus of elasticity of the specimen ends and can be evaluated as

$$
E_{\text {ends }}=\left(\frac{L_{T}}{E_{p} L_{\text {ends }}}-\frac{L_{\tau}-L_{\text {ends }}}{E_{s} L_{\text {ends }}}\right)^{-1}
$$

where $L_{T}=$ total specimen length; and $L_{\text {ends }}=25 \mathrm{~mm}$ not measured by $\delta_{s}$. Applying this equation to each individual specimen, the moduli for the ends, $E_{\text {ends, }}$ are $14.8 \pm 0.6$ and 17.8 $\pm 1.2 \mathrm{GPa}$ for the normal and high-strength concrete. It should be emphasized that $E_{\text {ends }}$ is a combination of concrete, capping compound, and interface between specimen and platen. This low stiffness would also contribute to larger $\varepsilon_{p}$, as discussed in the previous paragraph. Values of $E_{\text {ends }}$ are listed in Table 4. 
TABLE 4. Tangent Modull

\begin{tabular}{|c|c|c|c|c|c|c|c|c|}
\hline \multirow[b]{2}{*}{$\begin{array}{l}\text { Specimen } \\
\text { designation } \\
\text { (1) }\end{array}$} & \multicolumn{4}{|c|}{ Normal Strength (45 MPa) } & \multicolumn{4}{|c|}{ High Strength $(90 \mathrm{MPa})$} \\
\hline & $\begin{array}{c}E_{*} \\
(\mathrm{GPa}) \\
(2)\end{array}$ & $\begin{array}{c}E_{p} \\
(G P a) \\
(3)\end{array}$ & $\begin{array}{c}E_{c} \\
(\mathrm{GPa}) \\
(4)\end{array}$ & $\begin{array}{c}E_{\text {and }} \\
\text { (GPa) } \\
(5)\end{array}$ & $\begin{array}{c}E_{*} \\
(\mathrm{GPa}) \\
(6)\end{array}$ & $\begin{array}{c}E_{p} \\
(\mathrm{GPa}) \\
(7)\end{array}$ & $\begin{array}{c}E_{c} \\
(\mathrm{GPa}) \\
(8)\end{array}$ & $\begin{array}{c}E_{\text {onde }} \\
\text { (GPa) } \\
(9)\end{array}$ \\
\hline $\begin{array}{l}2.0 \mathrm{~A} \\
2.0 \mathrm{~B} \\
2.0 \mathrm{C} \\
2.0 \mathrm{D} \\
2.5 \mathrm{~A} \\
2.5 \mathrm{~B} \\
3.0 \mathrm{~A} \\
3.0 \mathrm{~B} \\
3.5 \mathrm{~A} \\
3.5 \mathrm{~B} \\
4.0 \mathrm{~A} \\
4.5 \mathrm{~A} \\
4.5 \mathrm{~B} \\
5.5 \mathrm{~A} \\
5.5 \mathrm{~B} \\
\end{array}$ & $\begin{array}{c}31.2 \\
34.0 \\
- \\
31.3 \\
33.3 \\
32.3 \\
32.0 \\
32.1 \\
32.2 \\
32.6 \\
32.7 \\
32.2 \\
32.7 \\
32.3 \\
\end{array}$ & $\begin{array}{c}27.5 \\
29.4 \\
- \\
-- \\
28.0 \\
29.9 \\
29.6 \\
28.8 \\
29.7 \\
29.8 \\
30.3 \\
30.9 \\
30.4 \\
31.1 \\
30.9 \\
\end{array}$ & $\begin{array}{c}29.7 \\
31.8 \\
- \\
- \\
30.1 \\
32.6 \\
31.7 \\
29.7 \\
31.7 \\
29.7 \\
32.3 \\
33.2 \\
30.5 \\
31.0 \\
30.9 \\
\end{array}$ & $\begin{array}{c}14.6 \\
14.7 \\
- \\
- \\
14.0 \\
15.2 \\
15.0 \\
13.5 \\
15.0 \\
14.7 \\
14.3 \\
15.6 \\
15.2 \\
15.3 \\
15.9 \\
\end{array}$ & $\begin{array}{c}42.5 \\
42.2 \\
- \\
- \\
42.3 \\
42.8 \\
41.5 \\
41.7 \\
42.1 \\
42.1 \\
42.0 \\
42.2 \\
42.6 \\
41.9 \\
41.7 \\
\end{array}$ & $\begin{array}{c}36.8 \\
35.7 \\
- \\
- \\
37.3 \\
37.5 \\
37.5 \\
37.6 \\
38.7 \\
38.9 \\
38.9 \\
38.3 \\
39.6 \\
39.5 \\
39.7 \\
\end{array}$ & $\begin{array}{c}40.5 \\
41.7 \\
- \\
42.4 \\
40.5 \\
39.8 \\
39.9 \\
40.1 \\
41.0 \\
41.9 \\
41.9 \\
41.5 \\
41.3 \\
41.2 \\
\end{array}$ & $\begin{array}{c}18.6 \\
16.8 \\
- \\
17.5 \\
17.4 \\
18.0 \\
17.5 \\
18.6 \\
19.1 \\
18.2 \\
14.8 \\
17.9 \\
17.7 \\
19.3 \\
\end{array}$ \\
\hline & $\begin{array}{r}32.4^{\mathrm{a}} \\
0.7^{\mathrm{b}}\end{array}$ & $\begin{array}{r}29.7^{\circ} \\
1.1^{\mathrm{b}}\end{array}$ & $\begin{array}{r}31.2^{\mathrm{a}} \\
1.2^{\mathrm{b}}\end{array}$ & $\begin{array}{c}14.8^{\mathrm{a}} \\
0.6^{\mathrm{b}}\end{array}$ & $\begin{array}{r}42.1^{\mathrm{a}} \\
0.4^{\mathrm{b}}\end{array}$ & $\begin{array}{r}38.2^{\mathrm{a}} \\
1.2^{\mathrm{b}}\end{array}$ & $\begin{array}{c}41.1^{\mathrm{a}} \\
0.8^{\mathrm{b}}\end{array}$ & $\begin{array}{r}17.8^{\mathrm{a}} \\
1.2^{\mathrm{b}}\end{array}$ \\
\hline
\end{tabular}

'Average.

'Standard deviation.

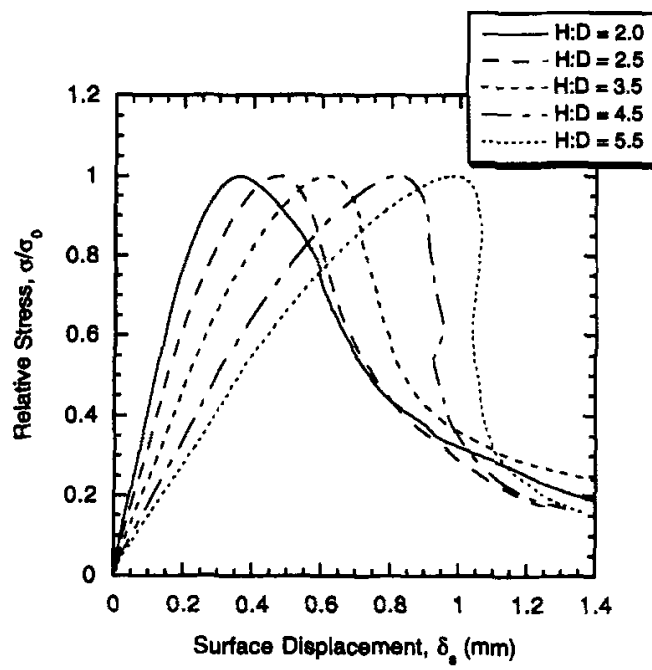

(a)

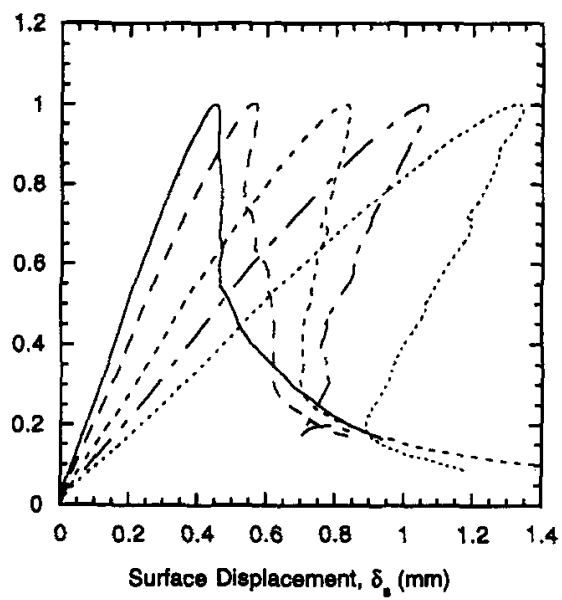

(b)

FIG. 7. Typical Stress-Displacement Behaviors for Range of Height-to-Dlameter Ratios: (a) Normal Strength; (b) Hlgh Strength

\section{Effect of Locallzation on Postpeak Behavior}

In the experiments performed in this investigation, no visible cracks were observed until after the peak stress. The first visible cracks were vertical and short. As the test continued, some spalling occurred around the point corresponding to about $45 \%$ of the peak stress (postpeak), and a distinct zone of failure was seen. As the lateral deformation occurred, longitudinal cracks extended from the zone of failure. The posttest evaluation of the specimens showed either a single shear plane or a cone-type failure. The cone-type failure is simply intersecting shear planes. As the shear plane(s) slides, the longitudinal cracks continued opening, and in some cases, extended the length of even the longest specimens. In the case when a cone forms, it can act as a wedge splitting the rest of the cylinder.

Fig. 7 compares the $\sigma-\delta_{s}$ curves for selected height-to-diameter ratios. The prepeak displacements are proportional to the specimen length; however, the postpeak curves show very significant changes. The longer the specimen, the steeper the curves become. When examining the $\sigma-\varepsilon_{s}$ curves shown in Fig. 8 , the prepeak portion of the curves shows no significant effect due to length; however, the postpeak curves are highly dependent on the specimen length. In fact, the localization can be visibly detected in Fig. 9. The length of the failure zone of the longer specimens is consistently about $300 \mathrm{~mm}$ or three times the specimen diameter. This finding is similar to observations by others testing tall, slender specimens (Markeset 1993; Rokugo and Koyanagi 1992).

The inelastic postpeak displacements, $\delta_{\text {inel, }}$, were calculated from the measured surface displacements, $\delta_{s}$, by using the line model as described earlier and defined in Fig. 10. This approach has been taken by others with mixed results (Bazant 1989; Hillerborg 1989; and Vonk 1992). This method assumes a linear unloading path from the peak stress with a slope equal to the modulus of elasticity of the specimen as shown in Fig. 10. If the line model of the damage zone is acceptable, then $\delta_{\text {inel }}$ should be the same regardless of the length of the specimen. This is essentially the case as shown in Fig. 11.

Fig. 11 shows the inelastic postpeak displacements, $\delta_{\text {inel }}$, for the normal and high-strength concretes. It can be seen from Fig. 11 that this model well fits the data for the postpeak displacements since all curves are reduced to a narrow band. All damage is not confined simply to what is described here 


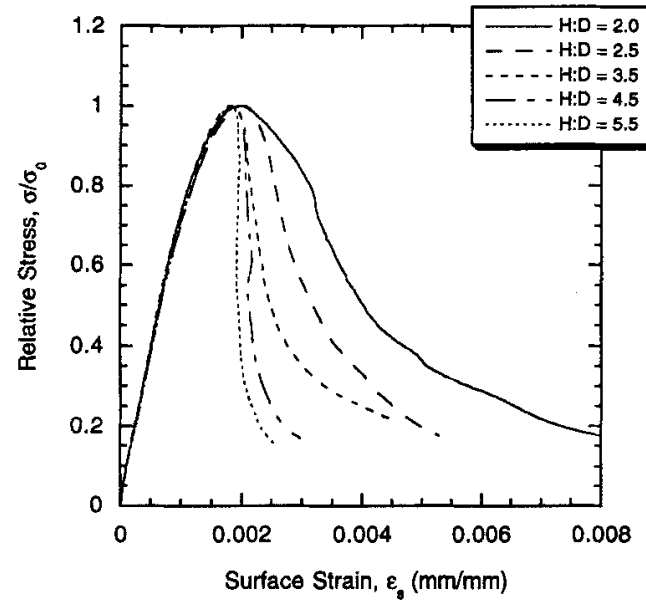

(a)

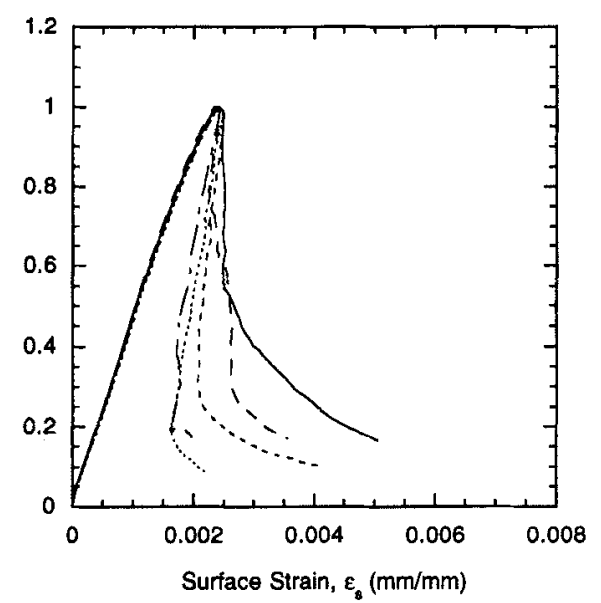

(b)

FIG. 8. Typical Stress-Strain Behaviors for Range of Height-to-Diameter Ratios: (a) Normal Strength; (b) High Strength

(a)

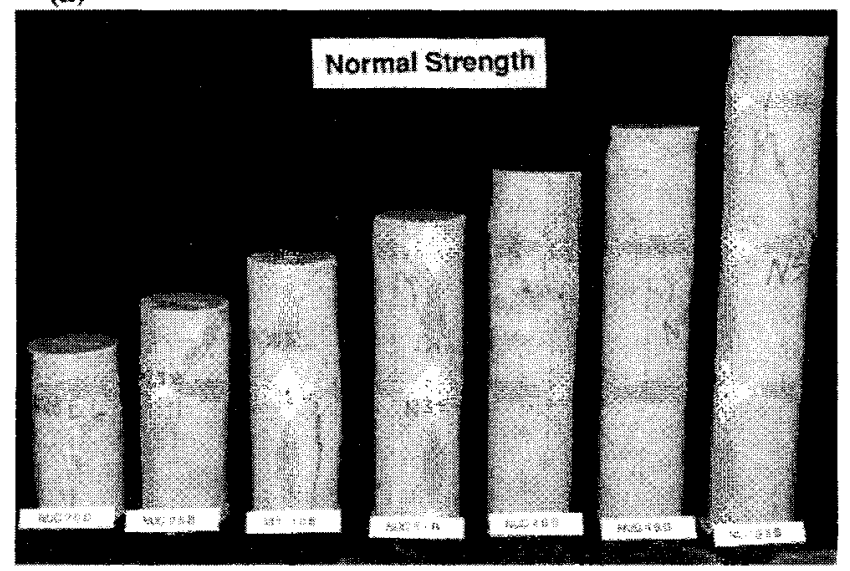

(b)

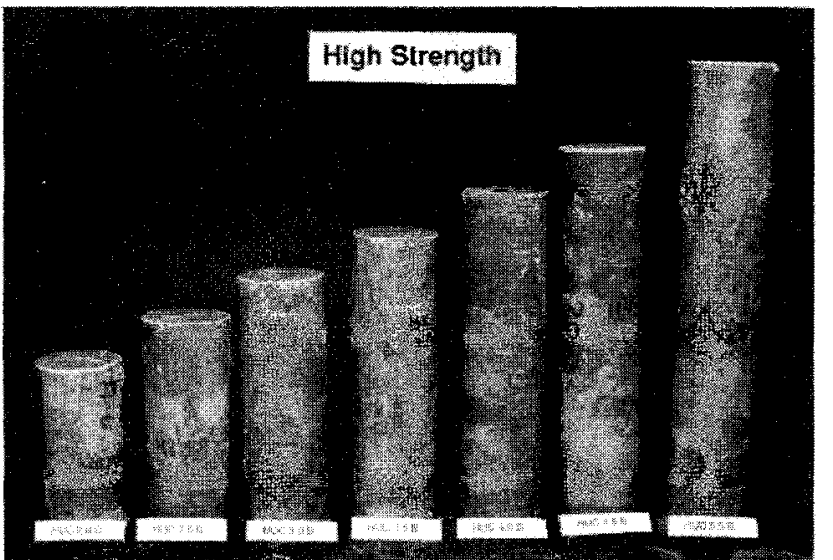

FIG. 9. Selected Normal and High-Strength Concrete Specimens after Testing: (a) Normal Strength; (b) High Strength

as the zone of localization; longitudinal splitting of the full specimens also occurs in some of the longer specimens. This longitudinal splitting occurs late in the postpeak and could account for some of the separating of the curves towards the tail end. However, since there seems to be no trend for these responses for different specimen lengths, it would be improper to discuss its modeling here. This suggests, however, that besides the bulk response and inelastic compression fracture zone, there may be a third component to the postpeak behavior of concrete in compression, and is discussed elsewhere (Markeset 1993). To conclude, for the data obtained in this investigation, the method of subtracting the elastic response from

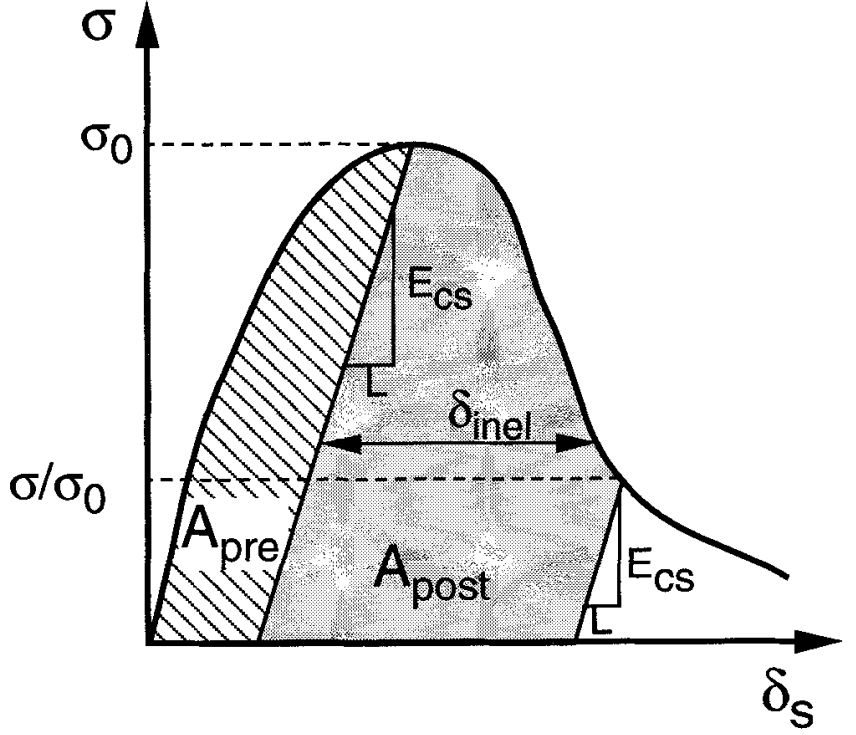

FIG. 10. Model for Determination of Prepeak and Postpeak Energies and Definition of $\delta_{\text {Inol }}$

the postpeak displacements can approximately describe the localization displacements, in spite of simplifying assumptions such as the linear unloading path and the line model for the length of the damage zone.

\section{Compression Fracture Energy}

To examine the compression fracture energy, the stress-displacement diagram was used and divided into two sections, as shown in Figs. 2 and 10. The prepeak energy per unit specimen area $\left(A_{\mathrm{pre}}\right)$ corresponds to the amount of energy dissipated by loading the specimen up to the peak stress and then unloading it completely (with the assumption that it would unload along a line parallel to the maximum stiffness). The postpeak energy per unit specimen area shown as $A_{\text {post }}$ in Fig. 10 corresponds to the area under the curves defined by the $\sigma-\delta_{\text {inel }}$ displacements of Fig. 11. For this part of the investigation, the postpeak compression fracture energies are defined from the peak stress until $\sigma / \sigma_{0}=33 \%$. These energies are plotted in Fig. 12 for the normal and high-strength concretes. The prepeak energies increase proportionally with specimen length as expected. The postpeak energies are essentially independent of specimen length. The independence of the postpeak compression fracture energy again confirms the occurrence of localization. Other investigators (Dahl and Brincker 1989; Rokugo and Koyanagi 1992) used the entire area under the load-dis- 


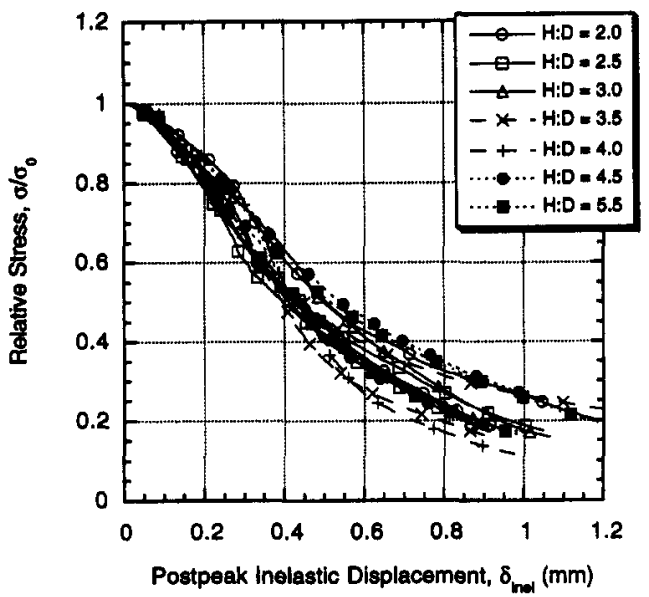

(a)

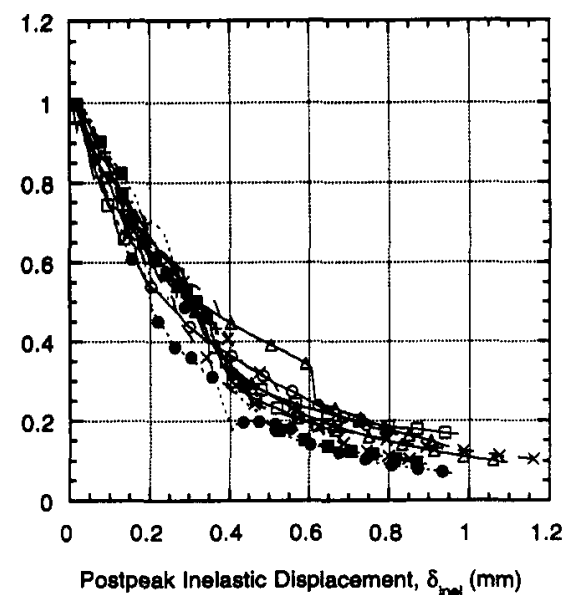

(b)

FIG. 11. Relative Stress versus $\delta_{\text {inel }}$ for Normal and High-Strength Concrete: (a) Normal Strength; (b) High Strength

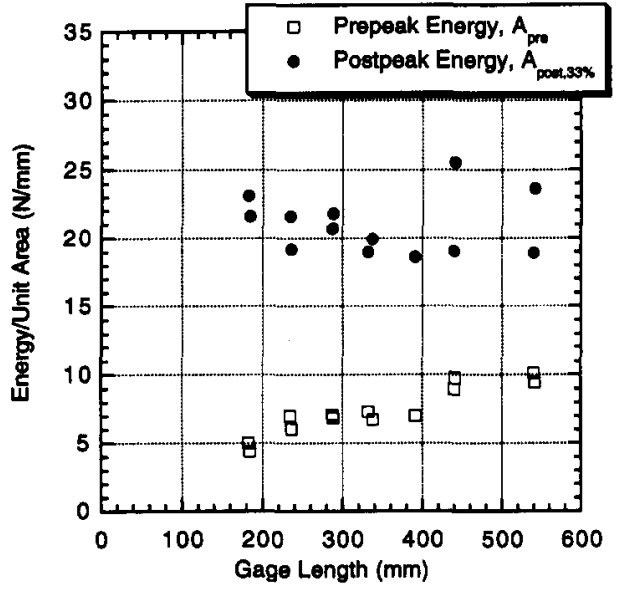

(a)

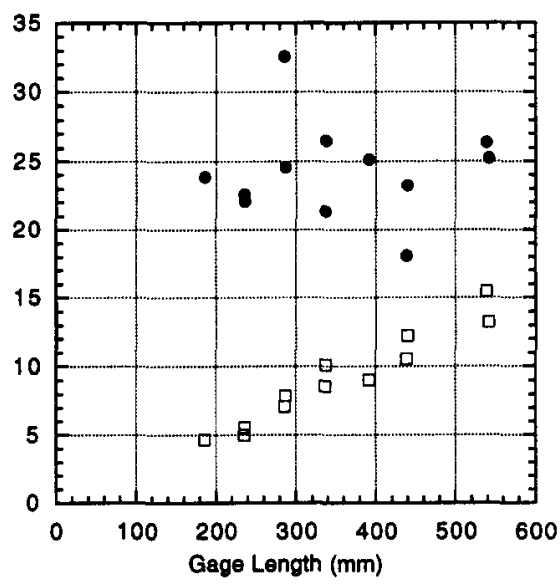

(b)

FIG. 12. Prepeak and Postpeak Energles per Unlt Cross-Sectlonal Area: (a) Normal Strength; (b) HIgh Strength

TABLE 5. Data from Rokugo and Koyanagl (1992)

\begin{tabular}{c|c|c|c|c|c}
\hline \hline & $\begin{array}{c}\text { Specimen } \\
\text { length" } \\
(\mathrm{mm}) \\
(2)\end{array}$ & $\begin{array}{c}\text { Compres- } \\
\text { sive } \\
\text { strength } \\
(\mathrm{MPa}) \\
(3)\end{array}$ & $\begin{array}{c}\text { Strain at } \\
\text { peak } \\
(\mathrm{mm} / \mathrm{mm}) \\
(4)\end{array}$ & $\begin{array}{c}\text { Prepeak } \\
\text { dissipated } \\
\text { energy } \\
(\mathrm{N} / \mathrm{mm}) \\
(5)\end{array}$ & $\begin{array}{c}\text { Postpeak } \\
\text { dissipated } \\
\text { energy } \\
(\mathrm{N} / \mathrm{mm}) \\
(6)\end{array}$ \\
\hline M-1 & 75 & 71.6 & 0.0047 & 7.7 & 52.2 \\
M-2 & 150 & 64.7 & 0.003 & 5.7 & 24.2 \\
M-4 & 300 & 62.5 & 0.0028 & 11.6 & 25.3 \\
M-6 & 450 & 62.7 & 0.0028 & 18.2 & 24.3 \\
P-1 & 75 & 49.7 & 0.0047 & 7.1 & 70.3 \\
P-2 & 150 & 39.2 & 0.0022 & 3.8 & 18.6 \\
P-4 & 300 & 39.2 & 0.0019 & 7 & 14.7 \\
P-6 & 450 & 38.8 & 0.0018 & 8.7 & 18.6 \\
F-1 & 75 & 56.4 & 0.0056 & 9.9 & 173.8 \\
F-2 & 150 & 47.7 & 0.0026 & 5.8 & 44.7 \\
F-4 & 300 & 46.4 & 0.0025 & 10.7 & 37.5 \\
F-6 & 450 & 43.7 & 0.0022 & 12.5 & 43.3 \\
\hline
\end{tabular}

placement or stress-displacement curves to compute the compression fracture energy that would correspond to adding $A_{\text {pre }}$ and $A_{\text {post }}$ from this investigation. To no surprise, they found the compression fracture energy to be dependent on specimen size. Rokugo and Koyanagi (1992) tested three types of materials, namely, a mortar, a plain concrete, and a fiber-reinforced concrete (designated $\mathrm{M}, \mathrm{P}$, and $\mathrm{F}$ in Table 5) with compressive strengths of 39,65 , and $48 \mathrm{MPa}$, respectively. Their specimens were $75 \times 75 \mathrm{~mm}$ in cross section and had length- to-width ratios of 1.0, 2.0, 4.0, and 6.0. Using stiffnesses measured from graphs in their paper, the prepeak and postpeak energies were recalculated with the model using linear-elastic unloading. The values obtained are shown in Table 5. The values from the mortar and plain concrete specimens closely match the values found in this investigation. The values for their shortest specimens (length to width of 1.0) are considerably higher than the other values. This is due to the confinement provided by the platens, which is also apparent by the considerably higher stresses and strains at peak for these specimens. The fiber-reinforced specimens showed considerably higher postpeak fracture energy than the plain concrete, as expected $(41.9 \mathrm{~N} / \mathrm{mm}$ versus $17.3 \mathrm{~N} / \mathrm{mm})$.

Vonk (1992) tested normal-strength concrete prisms of 50 $\times 50$ and $100 \times 100 \mathrm{~mm}$ cross sections and lengths of 50 , 100 , and $200 \mathrm{~mm}$ with lubricated ends to reduce constraint from the loading platens. He found that the postpeak compressive fracture energy increased with the specimen length and concluded that the compression fracture process within the failure zone is a combination of fracture and elastic unloading. His specimens, however, were relatively short and may have truncated some of the compression fracture zone, not allowing the full localized fracture zone to form. This further confirms that the fracture zone is $200 \mathrm{~mm}$ or more as observed visually from the failed specimens.

Fig. 13 shows how the postpeak compression fracture energy for the normal and the high-strength concretes accumulate as strain softening takes place. This shows that the amount of energy required to decrease the load-carrying capacity by a 


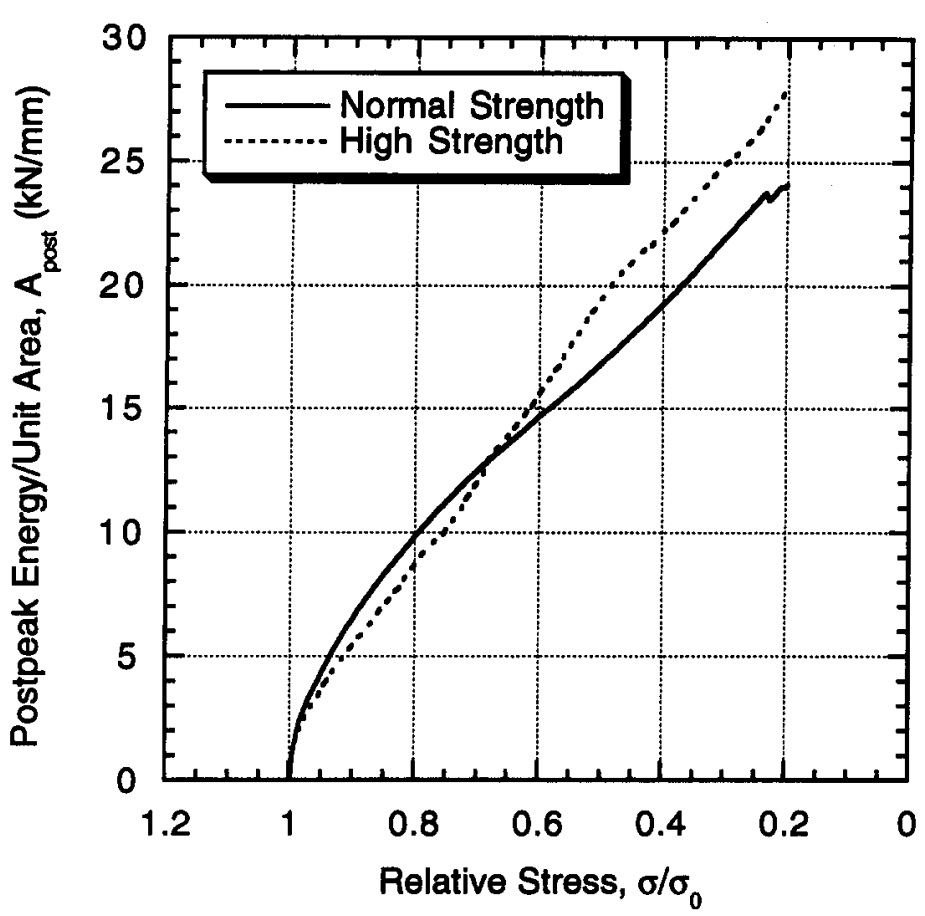

FIG. 13. Postpeak Energy as Function of Relative Stress for Normal and High-Strength Concretes

given fraction is about the same for normal and high-strength concrete. Relative to their compressive strengths, the highstrength concrete has less postpeak compressive fracture energy than the normal strength.

\section{CONCLUSION}

Localization occurs in compression failure of concrete. As specimens become longer, the total postpeak response of the specimen becomes steeper or more brittle. Severe snapback can occur particularly with high-strength concrete.

The method of partial elastic subtraction feedback control can be used to stably obtain the full stress-strain curve of concrete even when severe snapback occurs.

A model that subtracts the elastic response of concrete from the postpeak displacements can approximately describe the inelastic, localized deformations occurring during strain softening.

Prepeak energy per unit cross-sectional area increases proportionally with specimen length.

Postpeak energy per unit cross-sectional area does not change with specimen length for lengths greater than $200 \mathrm{~mm}$.

Normal and high-strength concretes absorb about the same amount of energy during failure, although it is far from being proportional to strength or energy during loading to peak.

\section{ACKNOWLEDGMENTS}

The research described in this paper is part of a continuing study sponsored by the National Science Foundation Grant "U.S.-Germany Cooperative Research on Strain Softening Response of High Strength Concrete." The writers also appreciate the support of NSF-ACBM.

\section{APPENDIXI. REFERENCES}

Bazant, Z. P. (1989). "Identification of strain-softening constitutive relation from uniaxial tests by series coupling model for localization." Cement and Concrete Res., 19(6), 973-977

Choi, S., Thienel, K.-C., and Shah, S. P. (1996). "Strain softening of concrete in compression under different end constraint." Mag. Concrete Res., London, England, 48(75), 103-115.

Dahl, H., and Brincker, R. (1989). "Fracture energy of high-strength concrete in compression." Fracture of concrete and rock: recent de- velopments, S. P. Shah, S. E. Swartz, and B. Barr, eds., Elsevier Applied Science, New York, N.Y., 523-536.

de Larrard, F., and Malier, Y. (1992). "Engineering properties of very high performance concretes," High performance concrete from material to structure, Y. Malier, ed., E \& FN Spon, London, England, 85114.

Elices, M., and Planas, J. (1989). "Material models." Rep. Fracture Mech. of Concrete Struct.: From Theory to Applications, RILEM, L. Elfgren, ed., Chapman and Hall Publishers, New York, N.Y., 16-66.

Glavind, M., and Stang, H. (1991). "Evaluation of the complete compressive stress-strain curve for high strength concrete." Fracture processes in concrete, rock and ceramics, J. G. M. van Mier, J. G. Rots, and A. Bakker, eds., E \& FN Spon, London, England, 749-759.

Hillerborg, A. (1989). "The compression stress-strain curve for design of reinforced concrete beams." Fracture mechanics: application to concrete, V. C. Li and Z. P. Bazant, eds., American Concrete Institute, Detroit, Mich., 281-294.

Hudson, J. A., Crouch, S. L., and Fairhurst, C. (1972). "'Soft, stiff and servo-controlled testing machines: a review with reference to rock failure." Engrg. Geol., 6(3), 155-189.

Jansen, D. C., and Shah, S. P. (1993). "'Stable feedback signals for obtaining full stress strain curves of high strength concrete." Proc., Utilization of High Strength Concrete, Lillehammer, Norway, 1130-1137.

Jansen, D. C., and Shah, S. P. (1994). "Load-deformation curves of normal and high strength concrete for a range of height to diameter ratios." Proc., ASCE 1994 Mat. Engrg. Conf. Infrastructure: New Mat. and Methods for Repair, K. D. Basham, ed., ASCE, New York, N.Y., $716-724$.

Jansen, D. C., Shah, S. P., and Rossow, E. C. (1995). “'Stress strain results of concrete from circumferential strain feedback control testing." $A C I$ Mat. J., 92(4), 419-428.

Kotsovos, M. D. (1983). "Effect of testing techniques on the post-ultimate behaviour of concrete in compression." Mat. and Struct., RILEM, London, England, 16(91), 3-12.

Markeset, G. (1993). "Failure of concrete under compressive strain gradients," PhD thesis, The Norwegian Inst. of Technol., Univ. of Trondheim, Trondheim, Norway.

Okubo, S., and Nishimatsu, Y. (1985). "Uniaxial compression testing using a linear combination of stress and strain as the control variable." Int. J. Rock Mech. Min. Sci. and Geomech. Abstract, Oxford, England, 22(5), 323-330.

Okubo, S., Nishimatsu, Y., and He, C. (1990). "Technical note: loading rate dependence of class II rock behaviour in uniaxial and triaxial compression tests - an application of a proposed new control method.", Int. J. Rock Mech. Min. Sci. and Geomech. Abstract, Oxford, England, 27(6), 559-562.

Rokugo, K., Ohno, S., and Koyanagi, W. (1986). "Automatical measuring system of load-displacement curves including post-failure region of concrete specimens." Fracture toughness and fracture energy of concrete, F. H. Wittmann, ed., Elsevier Science Publishers, B. V., Amsterdam, The Netherlands, 403-411.

Rokugo, K., and Koyanagi, W. (1992). "Role of compressive fracture energy of concrete on the failure behavior of reinforced concrete beams." Applications of fracture mechanics to reinforced concrete, A. Carpinteri, ed., Elsevier Applied Science, New York, N.Y., 437-464.

Shah, S. P., Gokoz, U., and Ansari, F. (1981). "An experimental technique for obtaining complete stress-strain curves for high strength concrete." Cement, concrete, and aggregates, CCAGDP, ASTM, Philadelphia, Pa., 3, $21-27$.

Shah, S. P., and Sankar, R. (1987). "Internal cracking and strain-softening response of concrete under uniaxial compression." ACI Mat. J., 84(3), 200-212.

Torrenti, J. M., Benaija, E. H., and Boulay, C. (1993). "Influence of boundary conditions on strain softening in concrete compression test." J. Engrg. Mech., ASCE, 119(12), 2369-2384.

van Mier, J. G. M. (1984), "Strain-softening of concrete under multiaxial loading conditions," PhD thesis, Eindhoven Univ. of Technol., Eindhoven, The Netherlands.

Vonk, R. (1992). "'Softening of concrete loaded in compression," PhD thesis, Eindhoven Univ. of Technol., Eindhoven, The Netherlands.

\section{APPENDIX II. NOTATION}

The following symbols are used in this paper:

$A_{\text {pre }}=$ prepeak compression fracture energy per unit specimen cross-sectional area;

$A_{\text {post }}=$ postpeak compression fracture energy per unit specimen cross-sectional area; 
$E_{c}=$ modulus of elasticity of concrete as measured by compressometer;

$E_{p}=$ modulus of elasticity of concrete as measured by platento-platen LVDTs;

$E_{s}=$ modulus of elasticity of concrete as measured by surfacemounted LVDTs;

$E_{\text {ends }}=$ average modulus of elasticity of ends of specimens;

$F=$ force;

$K_{d}=$ minimum tangential stiffness of descending branch;

$K_{0}=$ maximum initial tangential stiffness;

$K_{0 p}=$ maximum initial tangential stiffness measured by platento-platen LVDTs;

$L_{\text {ends }}=$ length of ends of specimens not measured by surface LVDTs $(=25 \mathrm{~mm})$;

$L_{T}=$ total specimen length;

$L_{z}=$ length of failure zone in band model;

$t=$ time;

$\alpha=$ coefficient that dictates proportion of elastic response is subtracted $\delta_{\text {inel }}=$ inelastic postpeak displacement defined by the line (crack) model

$\delta_{p}=$ displacement measured by platen-to-platen LVDTs;

$\delta_{s}=$ displacement measured by surface-mounted LVDTs;

$\delta_{T}=$ total displacement of specimen;

$\varepsilon_{B}=$ strain within bulk concrete zone;

$\varepsilon_{c}=$ strain measured by compressometer;

$\varepsilon_{c 0}=$ strain measured by compressometer at peak stress;

$\varepsilon_{p}=$ average strain measured by platen-to-platen LVDTs;

$\varepsilon_{p 0}=$ average strain measured by platen-to-platen LVDTs at peak stress;

$\varepsilon_{s}=$ average strain measured by surface-mounted LVDTs

$\varepsilon_{s 0}=$ average strain measured by surface-mounted LVDTs at peak stress;

$\varepsilon_{z}=$ uniformly distributed strain within failure zone for band model;

$\Theta=$ angle of axis rotation;

$\sigma=$ stress; and

$\sigma_{0}=$ peak stress. 